\title{
A UK advisory council for xenotransplantation?
}

Pigs rather than primates should be used for xenotransplants, and no pig-tohuman transplants should take place until an advisory body on xenotransplantation is set up to provide supervision. That is the conclusion of the UK's leading bioethics group, the Nuffield Council on Bioethics, in its February report, Animal to Human Transplants: The Ethics of Xenotransplantation. In the report, the Council says the risks associated with possible transmission of infectious diseases "have not been adequately dealt with," and thus concludes that it is "unethical" to begin clinical trials involving human beings.

The Council's investigation of xenotransplantation issues was initiated in January 1995, after it was approached by representatives of Imutran, Ltd., of Cambridge, a company that has genetically engineered pigs to express human complement inhibitor proteins to avoid the problem of hyperacute rejection. In September 1995, the company said it ex- pected the first pig-to-human heart transplant to take place at Papworth Hospital in Cambridgeshire early this year (Nature Medicine 1, 987; 1995).

The Advisory Committee on Xenotransplantation proposed

by the Council would assess the potential public health risks from infectious organisms of animals, establish the essential precautionary measures before any clinical human trials, and protect the interests of patients who receive xenografts. Patient consent to take part in xenotransplantation trials would have to be sought by professionals who are independent of the transplant team.

One important reason why the Council prefers the use of pigs to primates for xenotransplants is the greater concern about disease transmission from primates.

David White, research director at
Imutran, welcomes the report: "We want to be regulated," he says. "The last thing we need is a load of cowboys doing xenotransplants and giving it a bad name." However, White also says that the com-

\section{"The last thing we need is a load of cowboys doing xenotransplants and giving it a bad name."}

pany will not delay efforts to go into patients while waiting for a decision from the government on the setting up of an advisory committee. "The government is fully aware of where we are and where we intend to go," he said. The company will proceed with its ethics submission to the local ethical committee at Papworth Hospital and is still planning to perform the first pig-to-human transplant this year.

NUALA MORAN London, UK

\section{Prying open the African drug market}

An effort to lower the price of drugs and to promote generic drug distribution in the public and private sectors is under way in several African countries. Faced with skyrocketing prices in these countries have decided to implement new measures and to enforce new regulations to try to open the drug market to generic drugs, with the aid of international organizations, the European Community and bilateral French cooperation.

The move principally involves the fourteen French-speaking West African countries whose currency, the Communauté Française Africaine (CFA) franc, has been artificially buoyed by the Banque de France since colonization. In January 1994, a 50

A pharmacy in Zaire. In many African countries, only brand-name drugs are available, usually at prices higher than most patients can afford. for brand-name drugs, health officials

expensive in Africa than in France, because everyone, from the drug companies to the pharmacists, tries to make high profits from the drugs. (For pharmacists in Africa, unlike their French counterparts, the more expensive the drug, the higher their profit margin.) Furthermore, the range of prices between the different African countries is enormous, with drugs costing several times more in one country than another.

Following the devaluation of the CFA franc, the health ministers of the French-speaking countries held meetings to try to devise a common drug policy to promote generic drugs. The actions they are pursuing as a result of these meetings include adapting current regulations, managing central purchasing facilities, percent devaluation of the CFA franc resulted in a sharp rise of drug retail prices, leading the governments of these countries to realize the liability of a drug market based almost solely on the private sector and dominated by a few large - mainly French - pharmaceutical companies, and to take action to open the drug markets up to generics.

Currently, drugs in these countries are almost entirely available only under their brand names. These drugs are also more registering generic drugs regionwide, implementing quality control and manufacturing drugs locally. However, such measures will take time to show effects, so it is difficult now to assess the impact of the regulations that have only recently been passed.

CATHERINE TASTEMAIN Paris, France 